

\title{
En busca del VRCinema. Del cine proto-inmersivo al cine inmersivo
}

\author{
Searching for VRCinema. From \\ proto-immersive to immersive cinema
}

Laura Cortés-Selva*

Resumen: Esta investigación trata de demostrar que es con la aparición del VRCinema cuando comienza una etapa propiamente inmersiva en el ámbito cinematográfico. Para demostrarlo se emplea una metodología -fundamentalmente cualitativa- basada en un análisis de contenido de las fuentes más relevantes que versan sobre los elementos configuradores del triángulo inmersivo: la pantalla, el formato y la audiencia, lo que nos ha conducido a una aproximación a la definición del VRCinema.

Palabras clave: realidad virtual, cine inmersivo, pantalla cinematográfica, audiencia.

Abstract: The aim of this paper is to show that, it is with the introduction of VRCinema when a more precise immersive period is born. In order to verify that, a qualitative methodology has been applied, based on a content analysis of the most relevant sources which deal with the constitutive elements of the immersive triangle: screen, formats and audiences.

Keywords: virtual reality cinema, immersive cinema, screens, audience.

* Universidad Católica de Murcia. 


\section{Introducción}

Open your eyes, listen, smell and feel-sense the world in all its magnificent colors, depth, sounds, odors and textures- this is the cinema of the future!

(HEILIG, 2001, p. 226)

Ya sea a través de una madriguera o atravesando un espejo, la Alicia de Lewis Caroll personifica el deseo presente en el ser humano por explorar mundos nuevos distintos de su realidad inmediata. Aunque la ilusión de estar presente en otros universos ya existía veinte años antes del ingenio de los hermanos Lumière y cien años antes del nacimiento de la realidad virtual, con la invención del cinematógrafo ese sueño inmersivo se muestra más cercano. Hoy en día, el desarrollo en el ámbito de la realidad virtual está propiciando una experiencia audiovisual inmersiva que nos aproxima a lo que Bazin (1967, p. 17-22) acuñaba como el "mito del cine total".

En el ámbito de la Comunicación, desde una perspectiva centrada en la narración de historias basadas en la no ficción, destacan las experiencias inmersivas periodísticas de De la Peña et al. (2010) y de Eva Domínguez (2012a y 2012b), así como las de Gaudenzi (2009) y Gantier \& Bolka (2011), en el documental. En narraciones de historias de ficción destacan autores como Cheng y Cairns (2005) y McMahan (2003), centrados en los videojuegos, o Rose (2011), Boas (2013), Holmberg (2003), Ryan (2004), Turkle (1997), Rabinowitz (1998), Huhtamo (1995), Paul (1993) o Belton (1992) en el ámbito de la producción cinematográfica ficcional.

Sin embargo, ¿qué engloba el término inmersión? Boas (2013, p. 1) lo describe como la suspensión de la incredulidad provocada por los medios de comunicación, definición en la que destaca la importancia del aspecto psicológico inherente al proceso. Para Turkle (1997) es el hecho que se produce cuando la persona deja de percibir de forma clara su medio natural al concentrar toda su atención en un objeto, narración, imagen o idea que le sumerge 
en un medio artificial. Este proceso es consciente y, mientras dura, se tiene conocimiento de que es una situación irreal y artificial de la que se puede evadir cuando lo desee (RYAN, 2004).

Holmberg (2003) demuestra que los ideales inmersivos están presentes en el cine desde sus orígenes y reivindica el papel que otros dispositivos tecnológicos -anteriores a la invención de los hermanos Lumiére- han tenido en el proceso inmersivo. Por su parte, Huhtamo (1995) y Rabinowitz (1998) también centran sus investigaciones en las tecnologías relacionadas con la inmersión cinematográfica. De modo específico, Huhtamo (1995, p. 159) define la inmersión como la impresión, más o menos convincente, de estar presente en un mundo ficticio, aunque no sea real. El autor cita una serie de metáforas -"introducirse en el agua", "atravesar la pantalla o el espejo", "abandonar el cuerpo o cambiarlo", "perderse en un mundo simulado" o "navegar por el ciberespacio"relacionadas con una transición entre la realidad física inmediata y otra realidad.

En referencia al cine es necesario diferenciar entre la inmersión cognoscitiva y la física. La inmersión cognoscitiva consigue "transportar" en el sentido de crear la "ilusión de presencia", la sensación de inmersión que Belton (1992, p. 191192) describe como "ilusión de participación", de "sentirse parte de" -ya que el espectador permanece sentado en una butaca de una sala cinematográfica- un universo diegético gracias al conjunto de una serie de estrategias narrativas, estilísticas y tecnológicas características del medio cinematográfico.

En el caso de la inmersión física -que se produce a través de la vista, el oído y en ocasiones el tacto- el espectador "está presente" aunque de forma virtual a través de su avatar, en un espacio tridimensional creado virtualmente o capturado a través de cámaras de formato de $360^{\circ}$. Este tipo de inmersión requiere de la participación física del espectador para funcionar.

A lo largo de la evolución del cinematógrafo se han desarrollado diversas estrategias narrativas que han aumentado la 
inmersión cognoscitiva por parte del espectador, trasladándolo a un universo diegético a través de su identificación con los personajes y con el relato. Del mismo modo, mediante la utilización de elementos estilísticos -fundamentalmente visuales y auditivosse han perfeccionado diversas estrategias compositivas como la profundidad de campo, la iluminación, los movimientos de cámara, las dimensiones de los formatos y de las pantallas, y el sonido envolvente; todos ellos conjugados para incrementar la sensación de inmersión del espectador. Tanto los narrativos como los estilísticos se encuentran vertebrados por la tecnología y, en este sentido, es necesario mencionar la importancia que ha tenido su evolución para la existencia de unos y de otros, especialmente de la realidad virtual. De hecho, Manovich (1998a, p. 27) destaca la importancia de la evolución tecnológica en el ámbito de la informática, aunque incide en un elemento tecnológico más antiguo que ha sido fundamental para entender la inmersión cinematográfica: la pantalla, como marco de separación entre la realidad y la ficción. El "atravesar la pantalla" de los personajes de La rosa púrpura del Cairo (Woody Allen, The purple Rose of Cairo, 1985) actúa como metáfora visual de la relevancia de este elemento, en el que cobran protagonismo especialmente los sentidos de la vista y del oído. Aunque ha habido y continúan habiendo experiencias relacionadas con el olfato como Smell-O-Vision o Aromarama (LIMBACHER, 1968) o con el tacto como Percepto (LODGE, 2000), en el cine, la inmersión del espectador se ha producido fundamentalmente a través del sentido visual y del auditivo. La oscuridad de las salas, las pantallas panorámicas o el sonido envolvente forman parte de la experiencia cinematográfica y han contribuido a lograr una mayor inmersión del espectador en el universo creado. Por lo tanto, la vista es el sentido más relevante en la historia de la inmersión cinematográfica, vista que reposa fundamentalmente sobre una superficie: la pantalla. Definida por Manovich (1998a, p. 41) como un rectángulo plano, que surge en el Renacimiento con la pintura moderna, actúa como una ventana de separación entre el mundo real y el virtual. Desde 
los espectáculos de linterna mágica, panoramas y dioramas de los siglos XVIII y XIX, la pantalla ha evolucionado de muy distintos modos, gran parte de ellos destinados a aumentar la inmersión del espectador en el universo creado por esta dicotomía sensorial. No obstante, la pantalla actúa de intermediaria entre los dos elementos que conforman el triángulo inmersivo: el formato o soporte y el sujeto-espectador o audiencia.

\section{Metodología}

La metodología empleada en esta investigación -principalmente cualitativa- se basa en un análisis de contenido de las principales referencias bibliográficas relacionadas con la historia de las pantallas, de los formatos y de su vínculo con los espectadores. Para ello se ha diseñado una ficha ad hoc en la que figuran los elementos que conforman el triángulo inmersivo: las pantallas, el formato y los espectadores.

De la pantalla cinematográfica se obtienen, en primer lugar, los datos relativos a sus características físicas: sus dimensiones o altura y anchura, la mayor o menor curvatura y su planitud o relieve.

En cuanto al formato en el que vive la información proyectada en la pantalla es necesario especificar que, aunque en cinematografía el término alude a diferentes características ${ }^{1}$, en esta investigación se aplica en relación a la anchura del celuloide ( $35 \mathrm{~mm}$ es el formato más empleado por la industria pero también existe el $8 \mathrm{~mm}$, el $16 \mathrm{~mm}$, el $65 \mathrm{~mm}$ y el $70 \mathrm{~mm}$ ), así como a

1 Se entiende el formato como la anchura del celuloide $(8 \mathrm{~mm}, 35 \mathrm{~mm}$, $16 \mathrm{~mm}, 65 \mathrm{~mm}$ ); las dimensiones, forma y posición de las perforaciones de la película; las dimensiones, posición y orientación (horizontal o vertical) de cada fotograma; las características del fotograma que determinan cómo ha de ser proyectado (proporción de la altura y la anchura, o si la imagen es anamórfica o esférica); la velocidad de transporte de la película (número de fotogramas por segundo que se exponen y proyectan para una correcta impresión de movimiento); y la posición y tipo de cualquier banda sonora registrada en la película (óptica, magnética o digital) (ENTICKNAP, 2005, p. 47). 
la relación de aspecto (la altura y la anchura que dicho formato es capaz de proporcionar) y a la naturaleza analógica o digital del formato empleado.

En referencia al concepto sujeto-espectador que dirige su atención hacia la pantalla se contemplan datos relativos a la distancia de la pantalla al sujeto, así como los diferentes niveles de interacción con la narración y el tipo de interacción. También se tendrá en cuenta la experiencia de visionado desde el punto de vista físico -sentado, de pie- y social -visionado individual o colectivo-.

\section{El triángulo inmersivo:}

\section{la pantalla, el formato y el espectador}

Este apartado está dedicado a ofrecer un recorrido histórico que nos revele las transformaciones más importantes vinculadas a los elementos que definen el triángulo inmersivo. Lejos de querer ofrecer una completa historiografía de cada uno de ellos, nos detendremos en los detalles más relevantes que nos ayuden a entender el recién estrenado cine de realidad virtual o VRCinema.

\subsection{Del peepshow a la exhibición \\ cinematográfica per se}

En esta apartado se incluyen todas aquellas manifestaciones cinematográficas desarrolladas en espacios públicos y no gratuitas. Es la etapa que asiste a la transición del visionado a través de un orificio o peepshow hasta la exhibición propiamente dicha, se convierte en testigo de una serie de transformaciones significativas en los elementos configuradores del triángulo inmersivo. En primer lugar, se produce el nacimiento de la exhibición cinematográfica propiamente dicha, con la aparición de la pantalla, de formato y de la audiencia entendida desde una perspectiva clásica. 
Imagen 1: Kinetoscopio de Edison y Dickson.

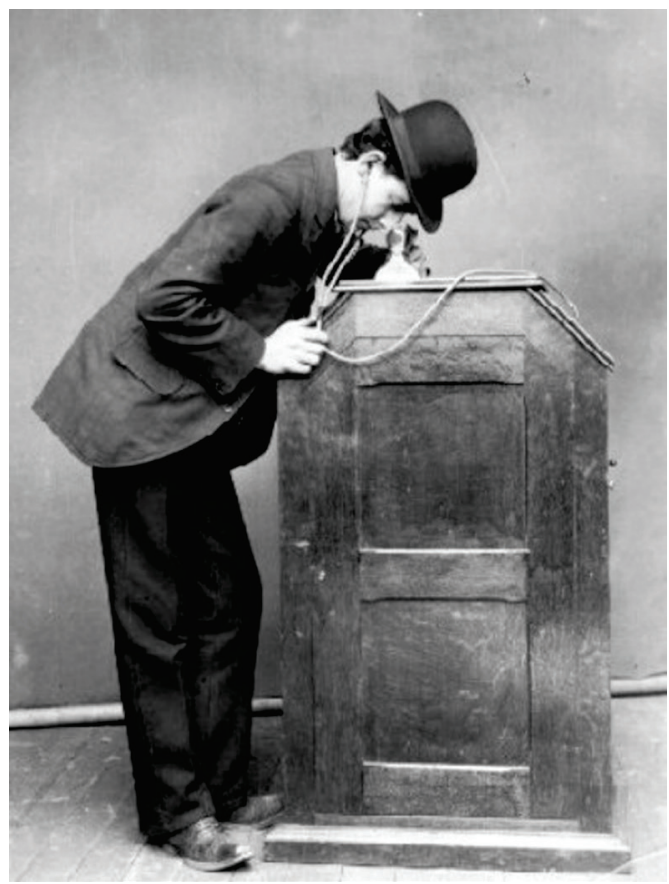

Fuente: imagen de dominio público.

El mismo espectador que en 1894 visionaba en una sala de Kinetoscopios (Kinetoscopio parlor) un cortometraje en bucle a través de un orificio tendría una percepción muy distinta 12 años después, convertido en parte de la audiencia de un Nickelodeon visionando cortometrajes proyectados en una pantalla plana colocada en una pared. De nuevo, ocho años después, en 1914, el mismo espectador tendría una percepción diferente al sentarse cómodamente en las salas de los palacios cinematográficos o cinema palace (ABEL, 2012).

Imagen 2: Los primeros espectadores cinematográficos en un salón de 
Kinetoscopios (Kinetoscopio parlor), en San Francisco.

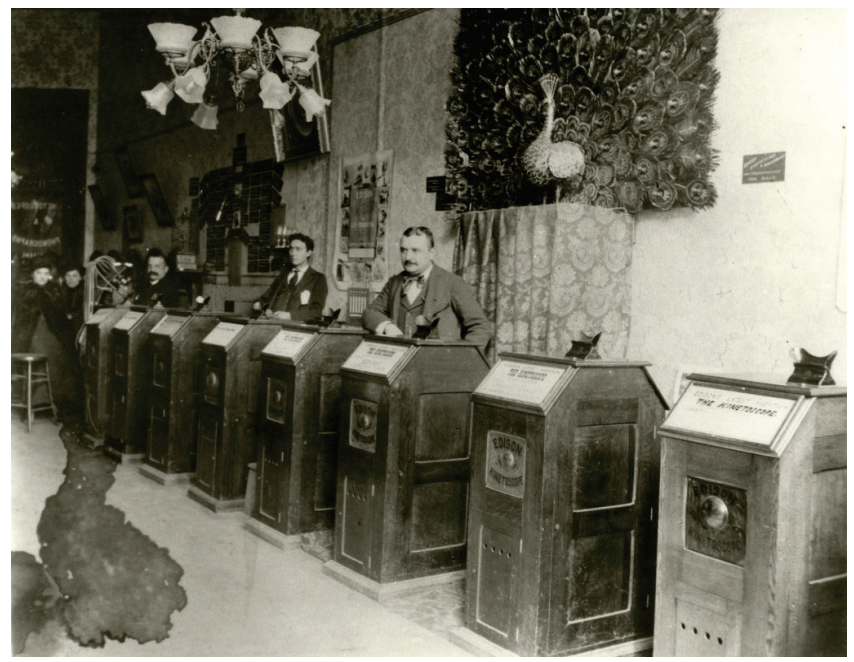

Fuente: imagen de dominio público via National Park Service/Edison Historic Site.

Por su parte, la pantalla de exhibición pasa de ser inexistente a constituirse como una pantalla per se, con la primera exhibición cinematográfica comercial que tiene lugar con el cinematógrafo de los hermanos Lumière en 1895. Con unas proporciones de 1,8 $\times$ 1,5 m (COE, 1981, p. 70), dicha pantalla plana evoluciona hasta alcanzar un máximo de 7,2 × 5,4 m presente en los Nickelodeon de mayor tamaño y en los palacios cinematográficos (BELTON, 1992, p. 35-36).

Es precisamente la necesidad de conseguir una imagen de mayor calidad que facilite la transición de la forma primitiva de visionado a través de uno o de varios orificios (peepshow), a la proyección en una pantalla cinematográfica propiamente dicha, lo que provoca el comienzo en 1896 de la primera revolución de los formatos. La estandarización del $35 \mathrm{~mm}$ analógico y de la relación de aspecto de 1.33:1 (3/4) por parte de la industria cinematográfica provoca que estos experimentos se detengan hacia 
1909 (PATTERSON, 1973; DICKSON, 1961; GREGORY, 1930).

Hacia 1926-27 se produce la segunda revolución de los formatos panorámicos a consecuencia de la aparición del sonido. La introducción de la banda sonora en el celuloide supone la reducción de la relación de aspecto de 1.33:1 a 1.15:1 y, con ello, el inicio de la experimentación con diferentes sistemas para lograr una proporción más panorámica (JONES, 1930, p. 32).

Las dimensiones más cuadradas del celuloide del cine mudo (1.33:1) abarcan un 31\% más del área de negativo que las del cine sonoro, es decir, el fotograma al que se le añade una banda de sonido ocupa un área inferior a la del celuloide del cine mudo. Sin embargo, en proyección, el celuloide con sonido ha de cubrir la misma proporción que la que se logra con el del cine mudo. Para lograrla, las estrategias creadas consisten en que, durante el rodaje del filme, se tiene en cuenta la altura y la anchura citadas mediante marcas en el visor y, en la proyección, se cubre con una máscara la parte superior e inferior de la imagen y se amplía hasta rellenar el área necesaria. De ahí que cada estudio cinematográfico optara por diferentes relaciones de aspecto: Paramount, Columbia y UA, empleaban la proporción 1.3:1; Fox, la 1.28:1; M-G-M, la 1.15:1; y Universal 1.34:1 y 1.15:1 (COWAN, 1930, p. 116). No obstante, dicha magnificación conlleva una pérdida de calidad de la imagen que conduce a que se siga experimentando con otras proporciones más panorámicas $(1.66: 1,1.85: 1$ y 2.35:1), así como con distintos tamaños de celuloide superiores al $35 \mathrm{~mm}^{2}$. Los numerosos ensayos que se suceden en esta etapa de la evolución cinematográfica no sobreviven al año 1931 debido, principalmente, a la alta inversión que requieren (PATTERSON, 1973, p. 42).

Durante este periodo se produce una transformación importante en la experiencia del espectador cinematográfico que, de estar de pie en una sala de Kinetoscopios, pasa a estar sentado 2 Entre ellos se encuentran el Polyvision (3 negativos de $35 \mathrm{~mm}$ ), el Grandeur $(70 \mathrm{~mm})$ de Fox, el Magnafilm $(56 \mathrm{~mm})$ de Paramount, el Natural Vision $(63,5 \mathrm{~mm})$, el Realife $(70 \mathrm{~mm})$ de MGM, o el Vitascope $(65 \mathrm{~mm})$ de Warners y U.A. (AMERICAN CINEMATOGRAPHER, 1955, p. 332-333, 368). 
en una sala cinematográfica. Ese visionado inicialmente individual -aunque en posible compañía de otras personas- se transforma en una experiencia en la que el espectador se sienta en una sala de cine junto a otros espectadores. Colocado a cierta distancia de la pantalla (off the screen), ese espectador asiste pasivo a una narración -todavía primitiva- en la que la estilometría y la tecnología se encuentran todavía en un inicial desarrollo.

Aunque el tipo de pantalla plana y bidimensional promueve un visionado central o interior en referencia al foco de atención del espectador, el reducido tamaño inicial de las pantallas en relación al espacio de las salas cinematográficas provoca que la atención del espectador se disperse.

\subsection{Del Cinerama al IMAX:}

\section{los grandes formatos cinematográficos}

La década de los cincuenta se caracteriza por ser una etapa en la historia del cine en la cual surgen principalmente experimentos relacionados con el triángulo inmersivo, especialmente en referencia a los formatos y a las pantallas cinematográficas que, con el objeto de recuperar a un espectador que prefiere quedarse en casa viendo la televisión, transforma la experiencia del espectador cinematográfico aumentando su vivencia inmersiva.

En la etapa comprendida entre 1952-1955, en cuanto al formato, la relación de aspecto varía del tradicional 1.33/1.37:1 al 1.66:1 (VistaVision) y al 2.77:1 (Cinerama); así como anchuras de celuloide de superior calidad a la del $35 \mathrm{~mm}$ como el $70 \mathrm{~mm}$; las dimensiones de las pantallas de proyección se incrementan desde $\operatorname{los} 7,2$ por 5,4 m alcanzados en el periodo anterior, hasta los $31,5 \times$ $10,5 \mathrm{~m}$ presentes en algunas salas de exhibición cinematográficas ${ }^{3}$. Los primeros formatos de pantalla panorámica que surgen en

3 Entre estas salas se encuentran las del Cinerama: (http://www. widescreenmuseum.com/widescreen/wingcr2.htm). 
la década de los cincuenta son los sistemas de cámara y de proyector triples, entre los que destaca el Cinerama (Paramount, 1952). Como el Polyvision, su precursor de la década de los veinte presente en filmes como Napoleon (Abel Gance, 1927), emplea 3 celuloides y 3 proyectores para ofrecer una imagen de grandes dimensiones con una calidad muy superior a la del estándar de $35 \mathrm{~mm}$. La imagen se proyecta sobre pantallas cóncavas que llegan a alcanzar los $5 \mathrm{~m}$ de profundidad y ofrecen una visión periférica de $146^{\circ}$ de anchura y $55^{\circ}$ de altura (BELTON, 1992, p. 168-170). Junto con la visión en profundidad proporcionada por elementos estilísticos como la perspectiva, la profundidad de campo, los movimientos de cámara, la luz o el color, la visión periférica contribuye a aumentar la experiencia inmersiva del espectador.

La importancia del Cinerama reside en el gran avance que supone en la conversión de los filmes "planos" en "tridimensionales", lo que favorece su experiencia inmersiva convirtiéndolo en un espectáculo sin precedentes (KIMBLE, 2002, p. 82-96). De hecho, uno de los anuncios de 1952 en referencia al primer filme producido con este sistema This is Cinerama (Merian C. Cooper, Gunther von Fritsch, Ernest B. Schoedsack, 1952) advertía: YOU -not the camera- but you are there..." (PAUL, 1993, p. 326). 
Imagen 3: Funcionamiento del formato Cinerama.

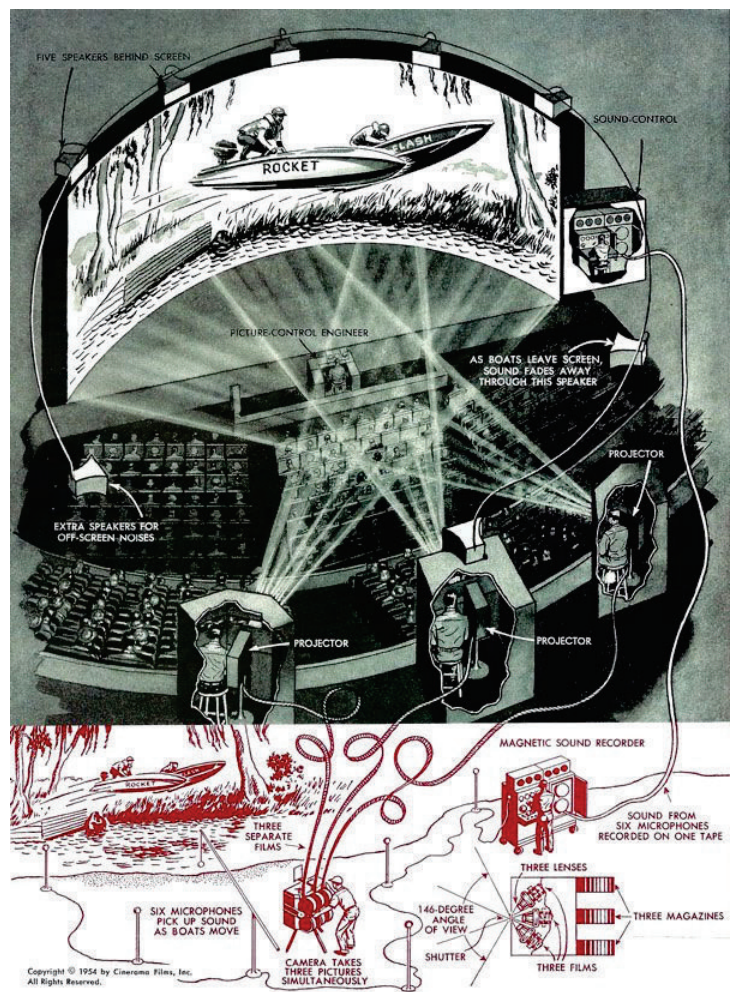

Fuente: www.3dfilmarchive.com

Además, introduce la ultra-panorámica relación de aspecto 2.77:1 y la obsolescencia de la anterior: 1.33/1.37:1, que comienza a identificarse con la exhibición televisiva. A pesar de la calidad de la imagen resultante, diferentes complicaciones técnicas inherentes al sistema -imposibilidad de mover la cámara, realizar determinadas angulaciones, distorsiones creadas por la fusión entre celuloides, iluminación compleja- así como implicaciones económicas favorecen su desaparición (DANIELS, 1962, p. 50-53; BRUN, 1954, p. 291, 301-302; LIGHTMAN, 1962, p. 537, 550556, y 1955, p. 243-244; NADEL, 1952, p. 11; ZONE, 2002, p. 


\section{8; AMERICAN CINEMATOGRAPHER, 1955, p. 654 y 674).}

Con el Cinerama como fuente de inspiración, durante la década de los cincuenta surge uno de los formatos anamórficos ${ }^{4}$ más importantes: el Cinemascope. Introducido en 1953, ofrece las mismas características espectaculares que el Cinerama pero, a diferencia del primero, es capaz de obtener con un sólo negativo de $35 \mathrm{~mm}$ una imagen ultra-panorámica proyectable en todas las salas cinematográficas (SAMUELSON, 2003, p. 70-77; HORA, 2003, p. 112).

Ahora bien, es necesario apuntar que aunque el Cinerama y el Cinemascope proyectan imágenes de $35 \mathrm{~mm}$ en pantallas que oscilan entre los 12,2 y los 19,8 m o más de anchura, otros formatos panorámicos magnifican la imagen de $35 \mathrm{~mm}$ más allá de la aconsejable proporción de 7,3 x 5,4 m produciendo un deterioro notable de la calidad. La solución a dicho problema supone la utilización de formatos de dimensiones superiores al $35 \mathrm{~mm}$, como el 70 mm (BODGER, 1962, p. 424-426, 440-441). Entre ellos se encuentran el IMAX y sus derivados (OMNIMAX, IMAX$3 \mathrm{D}$, etc.) que emplean celuloide de $70 \mathrm{~mm}$ de modo horizontal, ofreciendo una imagen con una calidad diez veces superior a la de un negativo estándar de $35 \mathrm{~mm}$. La experiencia IMAX se completa con la proyección de la imagen en unas salas especiales que difieren de las convencionales en cuanto al tamaño de la pantalla -con dimensiones que varían desde los $29 \times 21 \mathrm{~m}$ hasta los $3450 \mathrm{~m} 2$ de la pantalla más grande del mundo-; en referencia a la disminución de la distancia pantalla-espectador ${ }^{5} \mathrm{y}$ en la orientación de las butacas 4 Entre los formatos panorámicos de $35 \mathrm{~mm}$ que surgen en la década de los cincuenta se encuentran los esféricos y los anamórficos. Frente a la óptica estándar de los primeros, los anamórficos emplean un tipo de lente especial que comprime la imagen horizontalmente en el rodaje, y la descomprime posteriormente en la proyección. El resultado es una imagen que conserva la altura del negativo original pero dobla la anchura primitiva del celuloide, con lo que su correcta proyección implica la introducción de pantallas de dimensiones superiores a las tradicionales

$5 \quad$ La gran resolución del formato permite a la audiencia una mayor cercanía con respecto a la pantalla. 
-de hasta $23^{\circ}$ - con respecto a la pantalla.

A pesar de la calidad y espectacularidad de las imágenes resultantes, el alto presupuesto que subordina el empleo del IMAX ha supuesto que su aplicación se haya destinado principalmente a la realización de efectos especiales en largometrajes de ficción y a la producción de documentales. No obstante, directores como Christopher Nolan, defensor de la calidad del celuloide frente a la del formato digital, muestran la capacidad visual del formato empleándolo en sus filmes Batman begins (2005), The dark knight (2008), Inception (2010), The dark knight rises (2012) e Interestellar (2014). Otros directores que apoyan las bondades del formato son Quentin Tarantino, que lo emplea en la totalidad de The Hateful Eight (2015). Por su parte, existen directores que lo hibridan con el de 35 mm, como J.J. Abrams en Star Wars: Episode VII - The Force Awakens (2015) o Paul Thomas Anderson en The Master (2012).

Imagen 4: Formato IMAX.

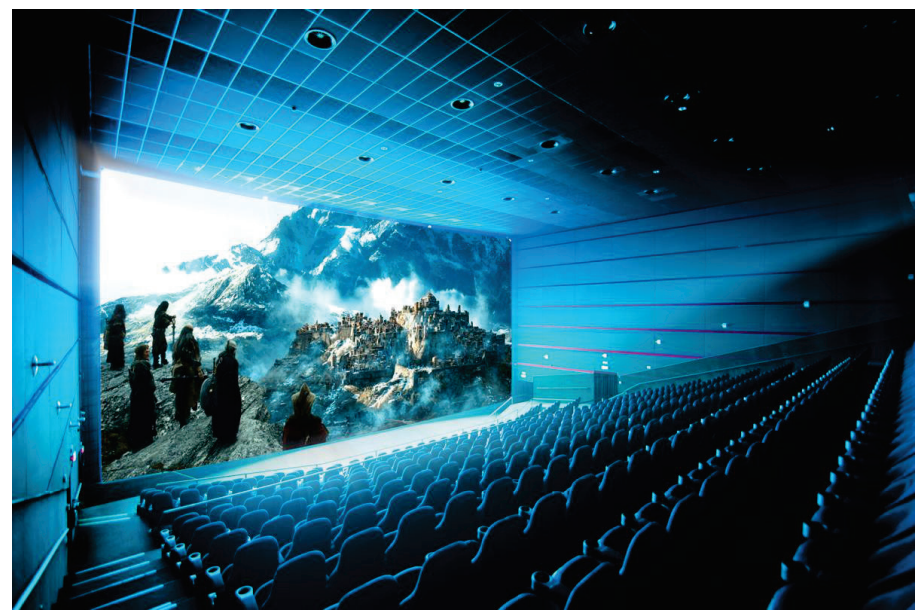

Fuente: imagen de dominio público

Durante este periodo, como en la etapa anterior, el 
espectador sigue sentado a cierta distancia de la pantalla (off the screen) y junto a otros espectadores, las dimensiones de la pantalla así como su curvatura promueven una participación más activa en el espectáculo, una "ilusión de participación” proporcionada por la ilusión de tridimensionalidad que ofrece el visionado periférico: la pantalla trata de envolver al espectador.

Imagen 5: Comparativa de las relaciones de aspecto de distintos formatos cinematográficos.

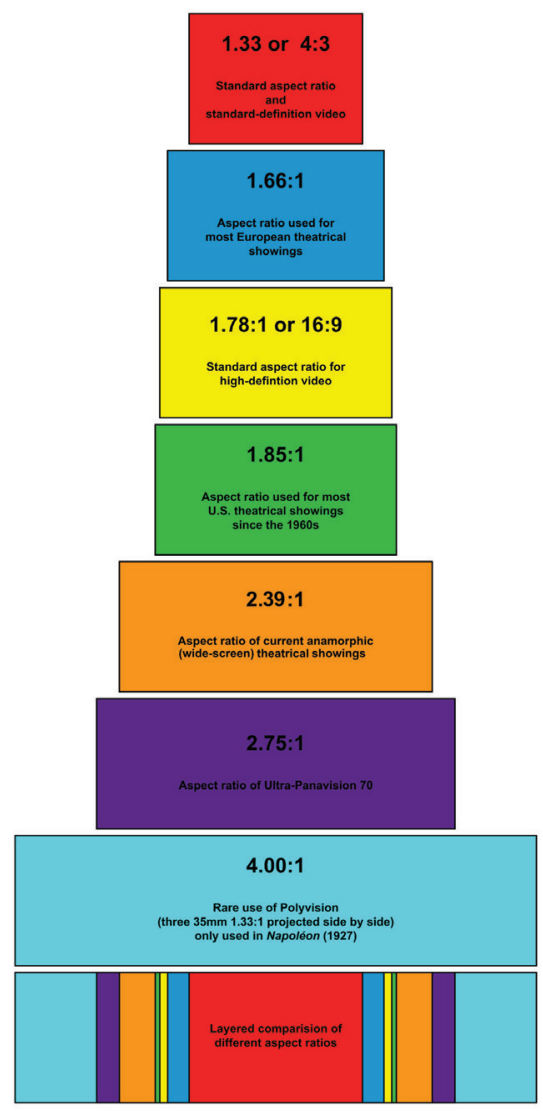

Fuente: imagen de dominio público 


\section{Del cine estereoscópico al VRCinema. El}

\section{nacimiento del cine de realidad virtual}

No es a mí a quien le gusta el cine, sino al cine a quien le gusto yo (José Sirgado en Arrebato, Iván Zulueta, 1973)

Eldeseodetridimensionalidadestápresentedesdelos orígenes del cine. De hecho, las reacciones de los primeros espectadores de la llegada del tren de los Lumière poseen un paralelismo con la de los primeros espectadores del cine estereoscópico o 3D ya que, en los inicios del cine, los movimientos hacia dentro y hacia fuera del cuadro son percibidos como estereoscópicos o tridimensionales (HOLMBERG, 2003, p. 138-139). Este efecto de tridimensionalidad también está presente en la etapa de los grandes formatos, no como resultado de la estereoscopia, sino de un conjunto de técnicas estilísticas y tecnológicas que logran crear la ilusión de tridimensionalidad. Se produce, por lo tanto, un contraste con los formatos de la etapa anterior, que la industria denominaba planos, bidimensionales o flat y que se caracterizan por una relación de aspecto de 1.33/1.77:1 (BELTON, 1992, p. 114).

Los primeros experimentos con la verdadera estereoscopia se inician con el nacimiento del cinematógrafo, aunque la década de los cincuenta -de nuevo- se considera el punto inicial a partir del cual comienza el desarrollo propiamente dicho de este tipo de cine tridimensional o 3D. Aunque nace motivado principalmente por atraer al espectador a las salas cinematográficas, acaba desapareciendo debido a razones económicas, narrativas y estilísticas. A pesar de los intentos fallidos por resurgir este tipo de cine durante los años setenta y ochenta, es finalmente a finales del siglo XX cuando renace con fuerza, con una técnica narrativa y estilística perfeccionada (PAUL, 1993, p. 322). Este renovado cine estereoscópico también tiene como objetivo prioritario aumentar la inmersión del espectador en la narración. Se caracteriza por dos 
etapas, en la primea domina el efecto de emergencia o paralaje negativo (negative parallax) que sucede cuando un objeto o persona “atraviesa" la pantalla (PAUL, 1993, p. 336), tal y como advertía el anuncio: A lion in your lap, a lover in your arms (BELTON, 1992, p. 190-191). Durante la segunda etapa se incrementa el efecto de inmersión o paralaje positivo (positive parallax), mediante el cual el espectador percibe, por primera vez, la sensación de presencia física en el universo diegético a través de la profundidad de la imagen creada por la estereoscopia, tal y como sucede en la versión 3D del filme Avatar (James Cameron, 2009).

Imagen 6: Publicidad del filme 3D Bwana Devil (Arch Oboler, 1952).

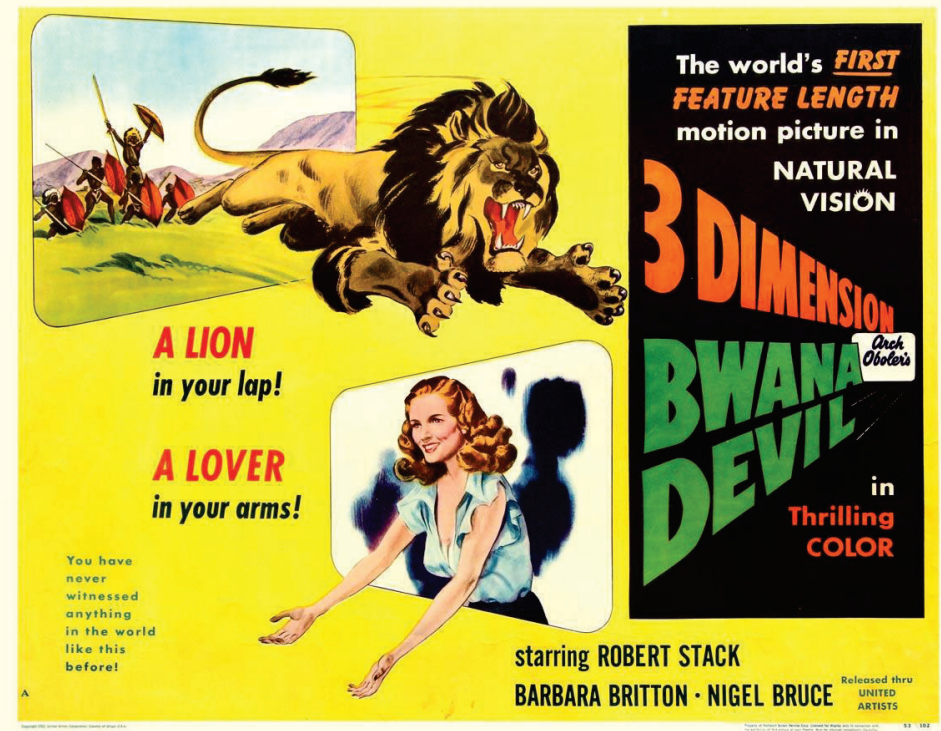

Fuente: www.3dfilmarchive.com

Con el cine 3D no existe una significativa modificación en cuanto al formato de proyección (analógico o digital dependiendo del filme), ni en referencia al tamaño de la pantalla (altura, la 
anchura o curvatura). La transformación se produce en relación a los efectos ópticos que provoca el sistema que, junto con el uso de gafas especiales, convierte a la pantalla en un elemento orgánico con relieve variable que, aunque conserva su distancia original con respecto al espectador, se acerca y aleja del mismo empleando el paralaje positivo o negativo según el momento narrativo. El cine $3 \mathrm{D}$ es capaz de provocar por primera vez, la interacción física por parte del espectador ya que, aunque sigue sentado en su butaca, comienza a moverse (especialmente los brazos) en un intento por alcanzar los distintos objetos tridimensionales que surgen de la pantalla, claro signo de su inmersión en el universo diegético.

Con una visión mejorada de sus antecesoras de los años cincuenta, las gafas especiales siguen siendo necesarias para visionar el renovado cine estereoscópico. Este dispositivo se convierte en un híbrido entre gafa y casco con la introducción del VRCinema.

Imagen 7: Espectadores de los años cincuenta con gafas especiales para el visionado de una película 3D.

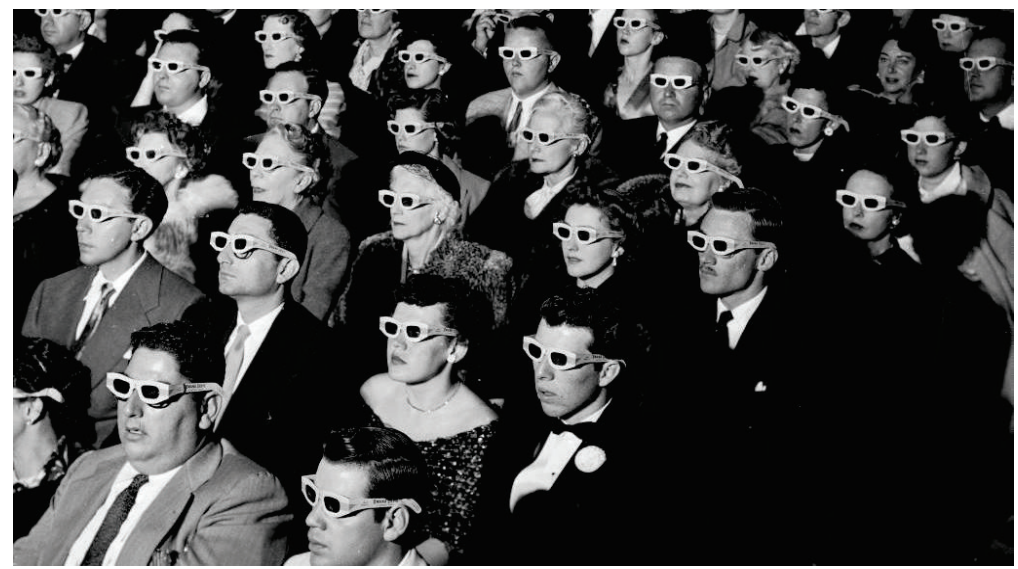

Fuente: www.3dfilmarchive.com 
Imagen 8: Espectador en la actualidad con un casco de realidad virtual.

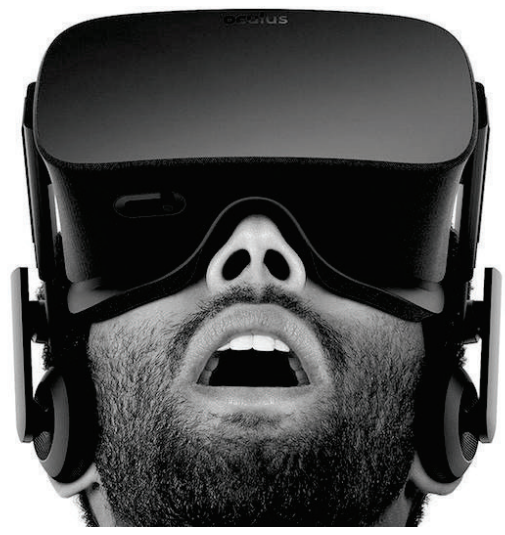

Fuente: www.oculus.com

Este VRCinema nace en la era multi-pantalla -multi-screenen la que han desaparecido las grandes pantallas de los años 50 y predominan las salas multiplex con pantallas de dimensiones estándar de 1.85:1, en las que se proyectan imágenes bidimensionales y tridimensionales. El VRCinema también convive con las micropantallas -micro-screens- entre las que se encuentran las televisivas, de ordenador, de tabletas y de móviles, y en las que se proyectan mayoritariamente imágenes bidimensionales.

Entre los antecedentes del VRCinema se encuentran los panoramas del siglo XIX, pinturas murales de enormes dimensiones que giraban alrededor de los espectadores, creando un espacio de $360^{\circ}$ (SÁNCHEZ-NORIEGA, 2002, p. 225). El Cinerama 360, cuyo heredero es el sistema OMNIMAX, también se encuentra entre sus antecedentes, así como los más recientes sistemas CAVE (Cave Automatic Virtual Environment), una habitación cuyas paredes son recubiertas por imágenes estereoscópicas que el espectador percibe tridimensionalmente a través del uso de unas gafas especiales.

Los antecedentes mencionados en las líneas anteriores demuestran que el VRCinema ha sido posible gracias al desarrollo 
de un conjunto de técnicas entre las que se encuentra la realidad virtual, rama de la informática cuyo objetivo es la creación de un mundo virtual con el que es posible interactuar a través del uso de unos dispositivos tecnológicos denominados Heads-Up Displays (HUD) o Head Mounted Displays (HMD) (BOAS, 2013, p. 1). Esta tecnología cuyos antecedentes se sitúan en los años 60 con el prototipo -“Headsight"- de Philco (SUTHERLAND, 1965, p. 506-508) cubre la totalidad del campo visual y auditivo del usuario. Incorpora tecnología que permite la visión tridimensional del espacio creado virtualmente o grabado con formato de $360^{\circ}$. Aunque existen diferentes resoluciones según el modelo ${ }^{6}$, la mayoría permite abarcar un ángulo de $360^{\circ}$ desplazando la cabeza y ofrecen una visión periférica capaz de alcanzar los $123^{\circ}$. Algunos modelos están dotados de un sistema de control de movimiento de la cabeza del usuario, que hace converger el punto de vista o perspectiva del mismo, con la del espacio virtual (HOLLOWAY \& LASTRA, 1995, p. 1-40). Aunque presente en algunos dispositivos, la tecnología relacionada con el tacto (Haptic), que permite tocar ciertos objetos incluidos en el espacio virtual a través de una especie de guantes, se encuentra en una fase inicial de desarrollo y no suele ser habitual.

El VRCinema se encuentra en un estadio inicial en el que conviven diferentes tipos de formatos narrativos de mayor y menor longitud, entre los que destacan los videojuegos, las estrategias promocionales, los reportajes y los documentales. Dejando de lado los videojuegos como Alien: Isolation (Dana Dorian, 2014), inspirado en la famosa saga cinematográfica, así como las experiencias inmersivas que funcionan como estrategias promocionales como Sleepy Hollow virtual reality experience o

6 Aunque existe una gran cantidad de modelos de HMD en el mercado (Oculus Rift de Oculus VR; Morpheus de Sony; o los productos ofrecidos por entre otros), muchos de ellos se caracterizan por ofrecer una baja calidad visual (SCHMALSTIEG; FAISSTNAUER; MAZURYK, 1995, p. 4-5). ImmersionVrelia se caracteriza por haber introducido un modelo que ofrece la más alta resolución de 1920 por 1080 píxeles. 
la realizada para el estreno de la película Interestellar, tal y como sucedía con las primitivas actualités que dominaron los orígenes del cine, las narraciones que -de momento- se están desarrollando en el VRCinema se enmarcan dentro del reportaje periodístico y del género documental. En concreto, Zero Point (Danfung Dennis, 2014) es un cortometraje documental pionero en ser rodado con un formato de $360^{\circ}$, creado específicamente para ser experimentado a través de los HMD. Muestra la trayectoria de los pioneros en realidad virtual, los investigadores y los desarrolladores, desde el simulador de entrenamiento para combate destinado al Departamento de Defensa de los Estados Unidos, a los laboratorios de investigación de la Universidad de Stanford.

Clouds (James George \& Jonathan Minard, 2013) es un producto multi-plataforma que incluye un largometraje documental y una instalación interactiva. Traslada al espectador a un espacio virtual en el que se exploran temas de creatividad e invención, de arte interactivo, de simulación, diseño computacional o visualización de datos. A través de más de 40 entrevistas a artistas, diseñadores, pensadores y hackers rodadas con el formato de cine tridimensional (RGBD), Clouds ha sido creado para ser experimentado a través de un HMD, aunque también puede ser visionado a través de pantallas convencionales.

Assent (Oscar Raby, 2014) es un documental que recrea digitalmente la ejecución realizada a un grupo de prisioneros capturados por el régimen militar chileno, en 1973. A través de la recreación digital del citado lugar y de la época, se sitúa a la audiencia en el punto de vista del padre del creador del documental, quien fue partícipe de los trágicos acontecimientos.

Polar Sea $360^{\circ}$ (Thomas Wallner y Stephanie Weimar, 2014) es un producto multi-plataforma que narra la expedición de tres hombres a través del "pasaje del noroeste", una ruta que conecta el océano Atlántico con el Pacífico a través del archipiélago del Ártico. Impracticable debido a los icebergs, desde hace unos años la ruta es navegable debido al deshielo. A través de los ojos de los inuit, Polar 
Sea ofrece al espectador la posibilidad de experimentar el Ártico en tres dimensiones. Incluye un documental de 90 minutos para la televisión (Polar sea: The Northwest Passage); una serie documental de 10 capítulos (Polar Sea $360^{\circ}$ ); así como un documental interactivo multimedia -The Polar Sea $360^{\circ}$ Journey- que combina el formato tradicional de dos dimensiones con el de $360^{\circ}$. Polar Sea también es una aplicación para móvil que permite que el espectador interactúe con la narración de un modo convencional a través de la pantalla táctil o vivir una experiencia inmersiva en el ártico a través de un HMD.

Con un formato más cercano al reportaje periodístico, Vice News VR: Millions march (Chris Milk \& Spike Jonze, 2015) explora la marcha de protesta que tuvo lugar en Nueva York con motivo del asesinato de Eric Garner mientras era arrestado por la policía. Rodado usando una cámara que captura imágenes de $360^{\circ}$, recorre la marcha a través de la reportera de Vice News VR, Alice Speri, situando al espectador en el centro de los acontecimientos. Los espectadores pueden vivir una experiencia inmersiva de $360^{\circ}$ través de la aplicación VRSE de iTunes para smartphones en conjunción con Google Play o directamente descargando la aplicación en un teléfono móvil y visionándola de modo tradicional. Aunque aún no se ha contemplado como dispositivo principal para experimentar el documental, la compañía Vice News estudia la posibilidad de que, más adelante, el filme pueda ser visionado a través de los HMD.

Finalmente, Clouds over Sidra (Chris Milk \& Gabo Arora, 2015) es un documental creado para Naciones Unidas que traslada al espectador a través de los ojos de una niña de doce años (Sidra), a un campo de refugiados de la guerra civil siria situado en Jordania. El documental es un encargo de Naciones Unidas cuyo objetivo principal es apoyar una campaña de concienciación sobre las condiciones de vulnerabilidad de ciertas comunidades, especialmente de los refugiados. El documental permite una experiencia inmersiva de $360^{\circ}$ a través del empleo del HMD, aunque también es posible su visionado de un modo tradicional. 
Tanto Hunger in Los Ángeles (2012) como Project Syria (2013) -ambas de Nonny De la Peña- son experiencias inmersivas que recrean digitalmente hechos reales a través de la utilización de fotografías, vídeos y audios procedentes de dicha realidad. Mediante la recreación virtual -en la que el audio es real- de un hecho que sucedió en la cola de un banco de alimentos de dicha ciudad, el espectador es capaz de experimentar en primera persona y a través del uso del HMD: la desesperación ante la falta de alimento.

Project Syria también supone una experiencia inmersiva que recrea dos escenas de la vida real. La primera narra el estallido de una bomba que sucede en una calle concurrida de Siria. La segunda escena traslada al espectador a un campo de refugiados en el que se experimenta, en primera persona y a través del uso de un HMD, el crecimiento exponencial de su población tal y como sucede en la vida real debido a la gran cantidad de refugiados que han de abandonar sus hogares.

\section{Conclusiones}

Llegados a este punto es necesario arrojar ciertas conclusiones sobre el tema abordado. A lo largo del desarrollo del artículo se ha constatado que la historia del cine puede dividirse en tres etapas inmersivas teniendo en cuenta que, a pesar de las promesas de ciertas tecnologías, todavía nos encontramos alejados de alcanzar la inmersión total. No obstante, es posible hablar de un primer periodo proto-inmersivo, que podría calificarse de primitivo debido al incipiente desarrollo de la narrativa, la estilística y la tecnología que provoca numerosos cambios en los elementos configuradores del triángulo inmersivo. No obstante, cuando se estabilizan, todavía existen varios elementos que dificultan la ilusión inmersiva como las salas cinematográficas que aumentan su tamaño de modo desproporcionado con respecto a las pantallas, que proyectan imágenes de reducidas dimensiones que transcurren ajenas a una audiencia que permanece pasiva y con más 
posibilidades de interactuar con el resto de espectadores que con el universo diegético creado.

Durante la segunda etapa denominada pre-inmersiva se produce una inmersión cognoscitiva propiamente dicha debido al perfeccionamiento de los elementos narrativos, estilísticos $\mathrm{y}$ tecnológicos, pero especialmente por los cambios que se suceden en los elementos configuradores del triángulo inmersivo. El crecimiento de las pantallas -que en algunos casos alcanza los 30 $\times 10,5 \mathrm{~m}$ - el incremento de su curvatura y la expansión del plano vertical de la relación de aspecto de la imagen -cuyo máximo exponente es el 2.77:1 del Cinerama- consiguen aumentar la atención del espectador colocándolo en el centro de una semiesfera con efecto envoltorio debido al difuminado o desenfoque de los bordes de la pantalla que, sin llegar a desaparecer, contribuye a fomentar la "ilusión de participación". No obstante, no deja de ser una ilusión debido a que el visionado sigue siendo colectivo y en un espacio público que nos recuerda que asistimos a una proyección de un conjunto de imágenes que continúan ajenas a la presencia de un espectador que, como en la etapa anterior, conserva el mismo papel pasivo sin posibilidad de interactuar con el universo diegético.

La unión de la inmersión cognoscitiva y la física -con diferentes niveles- es la que conduce a la tercera etapa denominada inmersiva, caracterizada por el surgimiento del VRCinema.

Desde el punto de vista narrativo y estilístico, el VRCinema incluye todas aquellas narraciones audiovisuales tridimensionales capturadas a través de cámaras de formato de $360^{\circ}$ o creadas virtualmente mediante tecnología digital, con una estética que puede permitirse una mayor o menor licencia en cuanto a la verosimilitud dependiendo de si se trata de una narración de ficción o de no ficción. En la actualidad predominan las narraciones vinculadas con el género documental y con el reportaje periodístico -en su mayoría con capacidad para visionarse en diferentes pantallas- que incluyen desde las que muestran universos completos hasta las que narran uno o dos hechos concretos. 
La inmersión cognoscitiva y física presente en el VRCinema es posible gracias a un conjunto de transformaciones fundamentalmente vinculadas con los elementos que forman parte del triángulo inmersivo y en las que el desarrollo del cine estereoscópico tiene un papel relevante. Una de las transformaciones más importantes está vinculada con el formato, pues este pierde su sentido clásico -en referencia a la anchura del celuloide, a su relación de aspecto y a su naturaleza analógica o digital- para convertirse en un formato digital de $360^{\circ}$. Una pantalla capaz de albergar este formato pasa de ser bidimensional a convertirse en una superficie esférica que ofrece una visión tridimensional que abarca la totalidad del espacio visible y en la que los bordes de la pantalla desaparecen, lo que supone otra de las transformaciones relevantes de este periodo. Por lo tanto, el espectador -a través de su avatar- pasa de estar fuera de la pantalla -off the screenentendida desde el punto de vista tradicional, a introducirse en el interior -in the screen- de un nuevo tipo de pantalla que lo envuelve por completo -wraparound screens-. El espectador pasa de estar sentado e inmóvil junto a otros espectadores en las salas de cine convencionales -visionado colectivo y público- a estar sólo, de pie y con un papel activo (al menos físicamente) -visionado individual y privado- en un espacio real que puede ser cualquiera, incluso una sala de cine.

A diferencia de lo que sucedía en las etapas anteriores en las que la pantalla y su proyección ignoraban la presencia del espectador, el VRCinema necesita su participación para funcionar, participación que contribuye de forma decisiva a la inmersión del espectador. Mediante el empleo de dispositivos tecnológicos -actualmente los HMD y los sistemas hápticos- el espectador experimenta en primera persona el universo digital en el que ha de mover la cabeza para abarcar todo el campo de visión y desplazarse físicamente por el espacio real para que tenga su paralelismo en el virtual. Al cubrir por completo el sentido de la vista y del oído, estos dispositivos eliminan cualquier elemento de distracción 
logrando una inmersión cognoscitiva y física de un espectador con dos cuerpos -real y virtual- presentes en dos espacios, real y virtual. Por lo tanto, frente a la ilusión inmersiva característica de las etapas anteriores, durante este periodo, el espectador siente su presencia -casi con mayor fuerza- en el universo virtual que en el real.

El hecho de ser un universo creado virtualmente implica que en el VRCinema las posibilidades de actuación son finitas, en consecuencia, el libre albedrío solo es una ilusión adquiriendo más el cariz de juego, game over. Si bien el nivel de desarrollo inicial implica una participación del espectador más cercana al voyeurismo -de un espectador que como un fantasma vaga entre el mundo real y el virtual- que al protagonismo -aunque algunos permitan tocar objetos o elegir alguna acción-, surgen una serie de cuestiones. Principalmente, si la posibilidad de interactuar con otros espectadores-personajes conformará universos virtuales en los que sea posible tomar cualquier tipo de decisión y que sus acciones tengan una repercusión real en dicho universo o si, por el contrario, el espectador seguirá condenado a un papel de títere manipulado por una instancia superior: el creador del universo virtual.

Con la introducción del VRCinema se transforman muchos de los elementos que han caracterizado al cine tradicional hasta la fecha. Este hecho nos enfrenta al reto de tratar de dar respuesta a nuevas preguntas que surgen en torno a los ámbitos que lo conforman: desde la narrativa (VR Storytelling) hasta la estilística (VR Style).

\section{Referencias bibliográficas}

ABEL, Richard. From Peep Show to Picture Palace: The early exhibition of Motion Pictures, in LUCIA, Cynthia; GRUNDMANN, Roy; SIMON, Art (eds.). The Wiley-Blackwell History of American Film, vol. 1, Origins-1918. Oxford: Wiley-Blackwell, 2012. 
AMERICAN CINEMATOGRAPHER. Summary of current widescreen systems of photography, American Cinematographer, vol. 36, n 11, November, p. 654 y 674, 1955.

BAZIN, André. The Myth of Total Cinema, in Bazin, André. What is Cinema? Vol. 1, Berkeley: University of California Press, 1967.

BELTON, John. Widescreen Cinema. Cambridge (Mass.): Harvard University Press, 1992.

BOAS, Yuri A. G. V. Overview of virtual reality technologies. In Interactive Multimedia Conference: Southampton. Disponible en: http://mms.ecs.soton.ac.uk/2013/papers/yavb1g12_25879847_ finalpaper.pdf, 2013.

BODGER, Lowell A. Ultra-wide screen systems, American Cinematographer, vol. 7, $\mathrm{n}^{\circ}$ 7, July 1962, p. 424-426, 440-441, 1962.

BRUN, Joseph. The Cinerama technique, American Cinematographer, vol. 35, $\mathrm{n}^{\mathrm{o}}$ 6, June, p. 291, 301-302, 1954.

CHENG, Kevin; CAIRNS, Paul. Behaviour, Realism and Immersion in Games, ACM Conference on Human Factors in Computing Systems, 2-7 april, Portland, p. 1272-1275, 2005.

COE, Brian. The History of Movie Photography. New York: Zoetrope, 1981.

COWAN, Lester. Camera and projector apertures in relation to sound-on-film pictures, JSMPE 14, $\mathrm{n}^{\mathrm{o}}$ 1, January, p. 116, 1930.

DANIELS, William. Cinerama goes dramatic, American 
Cinematographer, vol. 43, $\mathrm{n}^{\mathrm{o}}$ 1, January, p. 50-53, 1962.

DE LA PEÑA, Nonny (et al.). Immersive journalism: Immersive virtual reality for the First-Person Experience of News, Presence: Teleoperators and Virtual Environments, vol. 19, núm. 4, p. 291-301, 2010.

DICKSON, W.L.K. A brief history of the Kinetograph, the Kinetoscope and the Kineto-phonograph, en FIELDING, Raymond (ed.). A technological history of motion pictures and television. Berkeley: University of California Press, 1961.

DOMÍNGUEZ, Eva. Periodismo inmersivo: fundamentos para una forma periodística basada en la interfaz y la acción. Tesis doctoral de la Facultat de Ciències de la Comunicación de Blanquerna, 2012a.

. El reportaje inmersivo: la escena en 360 grados. [en línea], La Vanguardia.com, 18 de enero de 2012. Disponible en: http://blogs.lavanguardia.com/elcuartobit/elreportaje-inmersivo-la-escena-en-360-grados, 2012 b.

ENTICKNAP, Leo. Moving image technology: from zoetrope to digital. London: Wallflower press, 2005.

GANTIER, Samuel; BOLKA, Laure. L'experiènce immersive du web documentaire: études de cas et pistes de réflexion, Les Cahiers du Journalisme, Automme 2011, no. 22/23, p. 118-123, 2011.

GAUDENZI, Sandra. Interactive Documentary: towards an aesthetic of the multiple. London: University of London, Centre for Cultural Studies (CCS) of Goldsmiths, 2009. 
GREGORY, Carl Louis. The early history of wide films, Journal of Society of Motion Picture Engineers (JSMPE), 14, $n^{\circ} 1$, January, 1930.

HEILIG, Morton. The Cinema of the Future, reprinted in PACKER, Randall; JORDAN, Ken (eds.). Multimedia: From Wagner to Virtual Reality. New York/London: W.W. Norton, p. 219-231, 2001.

HOLLOWAY, Richard; LASTRA, Anselmo. Virtual Environments: A Survey of the Technology, SIGGRAPH'95 Course, Vol. 8 (A), p. 1-40, 1995.

HORA, John. Wrap shot, American Cinematographer, vol. 84, $\mathrm{n}^{\circ}$ 9, September, p. 112, 2003.

HOLMBERG, Jan. Ideals of Immersion in Early Cinema, Cinémas: revue d'études cinématographiques/Cinémas: Journal of Film Studies, vol. 14, $\mathrm{n}^{\circ}$ 1, 2003, p. 129-147, 2003.

HUHTAMO, Erkki. Encapsulated bodies in motion: Simulators and the quest of total immersion, in SIMON Penny (ed.). Critical Issues in Electronic Media. New York: Suny Press, p. 159-186, 1995.

JONES, Lloyd A. Rectangle proportions in pictorial compositions, JSMPE 14, nº 1, January, p. 32, 1930.

KIMBLE, Greg. The thrill of Cinerama, American Cinematographer, vol. 83, no 9, September, p. 82-96, 2002.

LIGHTMAN, Herb A. Filming the first Cinerama feature, American Cinematographer, vol. 43, $\mathrm{n}^{\circ}$ 9, September, p. 537, 550-556, 1962. 
Shooting Oklahoma in Todd-AO, American

Cinematographer, vol. 36, $\mathrm{n}^{\circ}$ 4, April, p. 243-244, 1955.

LIMBACHER, James M. Four aspects of the film: 3-D, Colour, Sound, Widescreen. Brussel and Brussel: New York, 1968.

LODGE, Nick. What can we learn from cinema of the 1950's, Invited paper presented at PRESENCE 2000, 3rd International Workshop on Presence, Delft, The Netherlands, 27-28 March, 2000.

MANOVICH, Lev. Towards an Archeology of the Computer Screen, in ELSAESSER, Thomas; HOFFMANN, Kay (eds.). Cinema futures: Cain, Abel or Cable?. The Screen Arts in the Digital Age. Amsterdam: Amsterdam University Press, p. 27-43, 1998.

MCMAHAN, Alison. Immersion, Engagement and Presence, en WOLF, M.J.P. \& PERRON, B. (eds.), The Video Game Theory Reader, New York, NY: Routledge, p. 77-78, 2003.

NADEL, Aaron. Cinerama, a step in the right direction, Ipro, vol. 27, $\mathrm{n}^{\mathrm{o}}$ 10, October, p. 11, 1952.

PATTERSON, Richard. Highlights from the history of motion picture formats, American Cinematographer, vol. 54, $\mathrm{n}^{\mathrm{o}} 1$, January, p. 40-41, 1973.

PAUL, William. The aesthetics of emergence, Film History, vol. 5, p. 321-355, 1993.

RABINOWITZ, Lauren. From Hale's Tours to Star Wars: Virtual Voyages and the Delirium of the Hyper-Real, Iris, $\mathrm{n}^{\circ}$ 25, 1998. 
ROSE, Frank. The Art of Immersion. How the digital generation is remaking Hollywood, Madison Avenue and the way we tell stories. New York, London: W. W. Norton \& Company, 2011.

RYAN, Marie-Laure. La narración como realidad. Barcelona: Paidós, 2004.

SAMUELSON, David W. Golden years. American Cinematographer, vol. 84, no 9, September, p. 70-77, 2003.

SÁNCHEZ-NORIEGA, José Luis. Historia del cine. Teoría y géneros cinematográficos, fotografía y televisión. Madrid: Alianza editorial, 2002.

SCHMALSTIEG, Dieter; FAISSTNAUER, Chris; MAZURYK, Thomas. Constructing a Highly Immersive Virtual Environment: A Case Study. Technical Report of Institute of Computer Graphics, Vienna University of Technology, TR-186-2-95-12, Austria, 1995.

SUTHERLAND, Ivan. The Ultimate display, Proceedings of IFIP 65 Congress, vol 2, p. 506-508, 1965.

TURKLE, Sherry. La vida en la pantalla. Barcelona: Paidós, 1997.

ZONE, Ray. "Wrap shot", American Cinematographer, vol. 83, $\mathrm{n}^{\circ}$ 9, September, p. 128, 2002. 